\title{
Apolipoprotein E genotype in familial Parkinson's disease
}

\author{
The French Parkinson's Disease Genetics Study Group (see appendix)
}

\begin{abstract}
APOE genotypes were compared in 57 cases of familial Parkinson's disease, 46 cases of sporadic Parkinson's disease, and 387 controls. The frequency of the APOE allele $\& 4$ was similar in patients with Parkinson's disease and controls, but the APOE allele $\varepsilon 2$, thought to be protective for dementia, was significantly more frequent in patients with sporadic Parkinson's disease than in controls. This is the first study of Parkinson's disease to include familial cases. It confirms the absence of association between the APOE allele $\varepsilon 4$ and this disease.
\end{abstract}

(F Neurol Neurosurg Psychiatry 1997;63:394-395)

Keywords: apolipoprotein E gene; Parkinson's disease;

The $\varepsilon 4$ allele of apolipoprotein $\mathrm{E}$ gene (APOE) is associated with early and late onset Alzheimer's disease. ${ }^{1}$ Because patients with Parkinson's disease occasionally become demented and the neuropathological hallmarks of Alzheimer's disease-neurofibrillary tangles and senile plaques - are found at postmortem in the brains of patients with Parkinson's disease, several studies of the APOE genotype in Parkinson's disease, with or without dementia, have been undertaken. ${ }^{2-7}$ Except in a small series of demented patients, ${ }^{4}$ no association was found between APOE allele $\varepsilon 4$ and Parkinson's disease. There have been, however, no studies of patients with familial Parkinson's disease, the pathogenesis of which may differ from that of the "sporadic" form of the disease. We have, therefore, compared APOE genotype distributions in 57 index cases with familial Parkinson's disease with those from 46 patients with isolated Parkinson's disease and 387 age and sex matched subjects randomly selected from a control sample of non-demented subjects.

Correspondence to: Dr Alexandra Dürr, INSERM U289, Hôpital de la Salpêtrière, $47 \mathrm{Bd}$ de l'Hôpital, 75651 Paris Cedex 13, France.

Received 17 December 1996 Accepted 12 February 1997

\section{Patients and methods}

All patients and controls were of French origin. The criteria for a definite diagnosis of Parkinson's disease were the presence of a pronounced response to levodopa and at least two of the following: bradykinesia, rigidity, rest tremor, or asymmetric onset. Exclusion criteria were the presence of at least one of the follow- ing: ophthalmoplegia, pyramidal or cerebellar syndrome, apraxia, prominent and early postural instability, urinary incontinence, or dementia within the first two years of evolution. Familial cases, defined by the presence of definite Parkinson's disease in at least two examined first degree relatives, were selected through a French clinical network (The French Parkinson's Disease Genetics Study Group). Isolated cases with no family history of Parkinson's disease among first and second degree relatives, verified by structured interviews of the patient and spouse, were recruited successively at the Fédération de Neurologie of the Hôpital de la Salpêtrière in Paris, France. Controls were age and sex matched selected subjects from a non-demented control sample. ${ }^{8}$

APOE genotypes were determined by polymerase chain reaction/restriction on DNA extracted from the blood of consenting patients. ${ }^{9}$ APOE allele and genotype frequencies were compared by $\chi^{2}$ test, with the Yates' correction when appropriate.

\section{Results}

Mean age at onset and at examination were similar in isolated and familial Parkinson's disease (table). The most frequent genotype in all groups was $\varepsilon 3 / \varepsilon 3$. Only three patients were demented; they belonged to the familial Parkinson's disease group and had the $\varepsilon 3 / \varepsilon 3$ APOE genotype. No $\varepsilon 4$ homozygotes were found. The allele distribution was significantly different in patients with familial and sporadic Parkinson's disease compared with controls $\left(\chi^{2}=8.16, \mathrm{P}=0.017\right)$. The comparison was not significant between familial and sporadic Parkinson's disease groups. The $\varepsilon 2$ allele was significantly more frequent in sporadic Parkinson's disease than in controls (odds ratio 2.45, 95\% confidence interval 1.15-5.21), but did not differ between familial and sporadic patients.

\section{Discussion}

Thus in familial Parkinson's disease, as in sporadic cases, there is no association with the APOE $\varepsilon 4$ allele. The lack of association between APOE $\varepsilon 4$ allele and Parkinson's disease was already reported in previous studies that did not distinguish between sporadic and familial cases. ${ }^{2367}$ Our data suggest that the APOE $\varepsilon 2$ allele may be associated 
Table 1 General characteristics, APOE genotypes, and allele frequencies in patients with Parkinson's disease (PD) and controls

\begin{tabular}{|c|c|c|c|}
\hline & Familial PD & Sporadic PD & Controls \\
\hline Number & 57 & 46 & 387 \\
\hline Mean( SD) age at onset (y) & $57(13)$ & $56(10)$ & \\
\hline Mean (SD) age at examination (y) & $65(12)$ & $65(9)$ & $67 \quad(9)$ \\
\hline $\operatorname{Sex} M / F$ & $29 / 28$ & $27 / 19$ & $215 / 172$ \\
\hline \multicolumn{4}{|l|}{ APOE genotype $\%(n)$ : } \\
\hline $2 / 2$ & $2(1)$ & 0 & $0.5(2)$ \\
\hline $2 / 3$ & $14(8)$ & $26(12)$ & 11 (43) \\
\hline $3 / 3$ & $70(40)$ & $57(26)$ & 62 (239) \\
\hline $4 / 2$ & 0 & 0 & $1.5(6)$ \\
\hline $4 / 3$ & $14(8)$ & $17(8)$ & $24 \quad(92)$ \\
\hline $4 / 4$ & 0 & 0 & $1 \quad(5)$ \\
\hline \multicolumn{4}{|l|}{ APOE allele frequency $\%$ : } \\
\hline$\varepsilon 2$ & 9 & 13 & 7 \\
\hline 83 & 84 & 78 & 79 \\
\hline$\varepsilon 4$ & 7 & 9 & 14 \\
\hline
\end{tabular}

with patients with sporadic Parkinson's disease. The association cannot be explained by the exclusion of patients with early dementia, possibly related to APOE $\varepsilon 4$ allele, as demented subjects were also excluded from the controls.

Although no conclusion can be drawn concerning the relation between familial and isolated Parkinson's disease, it is clear that an important risk factor for Alzheimer's disease, the APOE $\varepsilon 4$ allele, is less frequent in Parkinson's disease, whether sporadic or familial.

We are grateful to the families for their participation. We thank the Association France Parkinson and the French Health Ministry (PHRC) for financial support. Our special thanks to Merle Ruberg for critical reading of the manuscript.

Appendix: The French Parkinson's Disease Genetics Study Group

A Dürr, $S$ Medjbeur, $O$ Didierjean, $M$ Vidailhet, A-M Bonnet, D Grid, C Penet, A
Brice, Y Agid, INSERM U289 and Fédération de Neurologie, Hôpital de la Salpêtrière; $M$ Martinez, INSERM U358; J Feingold, INSERM U155, Paris; P Amouyel, INSERM CJF 95-05, Lille; M Borg, Hôpital Pasteur Nice; E Broussolle, Hôpital Neurologique Lyon; A Destée, CHR Lille; F Durif, Hôpital Fontmaure Chamalière; G Fénelon, Hôpital Tenon Paris; J-R Fève, Hôpital Laënnec Nantes; P Pollak, CHU Grenoble; O Rascol, Hôpital Purpan Toulouse; F Tison, Hôpital PellegrinTripode Bordeaux, C Tranchant, J-M Warter, CHR Strasbourg; M Vérin, Hôpital de Pontchaillou Rennes; F Viallet, CHU Aix en Provence; France.

1 Pericak-Vance M, Haines J. Genetic susceptibility to Alzheimer disease. Trends Genet 1995;11:504-8.

2 Marder K, Maestre G, Cote L, et al. The apolipoprotein $\varepsilon 4$ allele in Parkinson's disease with and without dementia. Neurology 1994;44:1330-1.

3 Benjamin R, Leake A, Edwardson JA, et al. Apolipoprotein $\mathrm{E}$ genes in Lewy body and Parkinson's disease. Lancet 1994;343:1565.

4 Arai $\mathrm{H}$, Muramatsu T, Higuchi S, Sasaki H, Trojanowski JQ. Apolipoprotein E gene in Parkinson's disease with or without dementia. Lancet 1994;344:889.

5 Koller WC, Glatt SL, Hubble JP, et al. Apolipoprotein E genotype in Parkinson's disease with and without dementia. Ann Neurol 1995;37:242-5.

6 Poduslo SE, Riggs D, Rolan T, Schwankhaus J. Apolipoprotein E and B alleles in Parkinson's patients. Neurosci Lett 1995;194:145-7.

7 Whitehead AS, Bertrandy S, Finnan F, Butler A, Smith GD, Ben-Shlomo Y. Frequency of the apolipoprotein E $\varepsilon 4$ allele in a case-control study of early onset Parkinson's disease. $\mathcal{f}$ Neurol Neurosurg Psychiatry 1996;61:347-51.

8 Amouyel P, Cottel D, Berr C, Vidal O, Brousseau T. $\varepsilon 4$ Allele of the apoliprotein $\mathrm{E}$ gene is a potent risk factor for cognitive impairment. Neurobiol Aging 1994,15:S43.

9 Hixson JE, Vernier DT. Restriction isotyping of human apolipoprotein $\mathrm{E}$ by gene amplification and cleavage with HhaI. F Lipid Res 1990;31:545-8. 